\title{
Plasma polyunsaturated fatty acid pattern in active inflammatory bowel disease
}

\author{
M Esteve-Comas, M Ramírez, F Fernández-Bañares, A Abad-Lacruz, A Gil, E Cabré, \\ F González-Huix, J Moreno, P Humbert, M Guilera, J Boix, M A Gassull
}

\begin{abstract}
Plasma fatty acid patterns were assessed by gas liquid chromatography in $\mathbf{7 3}$ patients with active inflammatory bowel disease and 107 healthy controls. The influence of the disease activity on fatty acid profile was also investigated. Plasma fatty acid patterns in patients with ulcerative colitis and Crohn's disease were similar. Plasma C18:3n3 and C22:6n3 were significantly higher in active ulcerative colitis $(p=0.0143$ and $p<0.00001$ respectively) and in Crohn's disease ( $p<0.00001$ for both) than in controls, whereas $\mathrm{C} 20$ :3n6 was significantly lower in patients than in controls, both in ulcerative colitis $(p=0.0001)$ and in Crohn's disease $(p=0.0041)$. In more severe disease, plasma polyunsaturated fatty acid concentrations fell with a significant stepwise decrease in the desaturation index $(p=0.0031$ in ulcerative colitis and $\mathbf{p}=\mathbf{0 . 0 3 5 5}$ in Crohn's disease). Even in patients with severe disease, however, plasma $n 3$ fatty acids (C18:3n3 and C22:6n3) never fell below those of healthy controls. These findings suggest that in active inflammatory bowel disease, an increased biosynthesis might coexist with an increased consumption of polyunsaturated fatty acids. These observations may be of relevance in the pathogenesis of the disease as polyunsaturated fatty acids are involved in tissue eicosanoid synthesis and cellular membrane function, including that of immunocompetent cells. These results also question the rationale of using $n 3$ polyunsaturated fatty acids in the treatment of inflammatory bowel disease.
\end{abstract}

(Gut 1992; 33: 1365-1369)

Polyunsaturated fatty acids have essential biological functions. As part of the structure of cell membrane, they exert control on its intrinsic proteins - for example, enzymes, receptors - by inducing changes in membrane fluidity. ${ }^{12}$ In addition, the long chain polyunsaturated fatty acids, dihomo- $\tau$-linolenic (C20:3n6), ${ }^{3}$ arachidonic (C20:4n6), ${ }^{45}$ and eicosapentaenoic (C20: 5 n3) ${ }^{6}$ acids are the precursors of eicosanoids. Some of the arachidonic acid derived eicosanoids (prostaglandin $\mathrm{E}_{2}$, leukotriene $\mathrm{B}_{4}$, and thromboxane $\mathrm{A}_{2}$ ) have been incriminated in the pathogenesis of inflammatory bowel disease, because their concentrations increase in the inflamed intestinal mucosa in the acute phase of the disease..$^{7-12}$

There are four different polyunsaturated fatty acid series which share the same desaturases and elongases for their synthesis. ${ }^{131+}$ Their affinity for these enzymatic systems are different, however. In addition, the components of the differ- ent fatty acid series are not interconvertible in vivo. ${ }^{13}$ These properties have allowed modification of the eicosanoid synthesis by producing changes in dietary polyunsaturated fatty acids. ${ }^{1516}$ Dietary supplementation with eicosapentaenoic and docosahexaenoic acids rich fish oil induces the appearance of triene prostaglandins and thromboxanes ${ }^{1718}$ and pentaene leukotrienes $^{19}$ with attenuated inflammatory effects. ${ }^{17-19}$ The therapeutic efficiency of eicosapentaenoic acid (C20:5n3) as an antiinflammatory agent in experimental models of inflammation ${ }^{2021}$ and therapeutic trials in patients with rheumatoid arthritis ${ }^{22}$ and inflammatory bowel disease $\mathrm{s}^{23-25}$ is, however, at least, controversial.

Plasma polyunsaturated fatty acid patterns have not been previously assessed in ulcerative colitis whereas information in Crohn's disease is limited. ${ }^{26}{ }^{27}$ It would be of scientific interest to know of plasma polyunsaturated fatty acids profile in inflammatory bowel disease as it might have both pathophysiological and therapeutic implications.

The aim of this study was to prospectively assess the plasma fatty acid pattern in patients with active inflammatory bowel disease compared with healthy controls and to ascertain whether the activity of the disease has any influence upon plasma concentrations of fatty acids.

\section{Methods}

PATIENTS

Seventy three consecutive patients (40 men, 33 women) with active inflammatory bowel disease (median age 32.5 years; ranges 14-81) were included in the study at admission or when first seen in the outpatient clinic. Forty one had ulcerative colitis and 32 had Crohn's disease. The diagnosis of inflammatory bowel disease was based upon clinical, endoscopic and radiological findings and was supported by biochemical, scintigraphic and pathological features. Exhaustive microbiological analysis were performed in order to exclude patients with gastrointestinal infection. These included in all cases stool culture, special stool culture and serologic tests for Yersinia enterocolitica, repeated fresh stool examination (three to six) for parasites and chlamydia direct immunofluorescent test. Clostridium difficile toxin assays, biopsy examination and culture for mycobacteria and immunohistochemical detection of herpes virus and cytomegalovirus in biopsy specimens were carried out in particular cases.

The activity of the disease was assessed by 
means of the Truelove's index for ulcerative colitis $^{28}$ and the Van Hees's index for Crohn's disease. ${ }^{29}$ According to the activity index, the attack was classified as mild, moderate, or severe. Twelve patients with ulcerative colitis had mild, 19 moderate, and 10 severe attacks. In Crohn's disease, the activity was mild in 15, moderate in 11 , and severe in six patients. Data regarding diet, nutritional status, ${ }^{30}$ and drugs were also carefully recorded.

\section{CONTROLS}

One hundred and seven healthy individuals (46 men, 61 women; median age 32.5 years; ranges 18-76) living in an urban area in the outskirts of Barcelona (Catalunya, Spain) acted as a control group. All subjects were well nourished according to previously described criteria. ${ }^{30}$ The existence of both acute and chronic illnesses was ruled out on the basis of a complete anamnesis and full clinical and biological examination including routine haematological counts, serum glycaemia, total cholesterol, triglycerides, and renal and liver function tests (Technicon SMA-20 Autoanalyzer). Those with previous history of diseases or surgical procedures capable of influencing the absorption of macro or micronutrients were also excluded from the study. All subjects, including elderly people, lived at their family home and were on a balanced western diet. Intake of monotonous, deficient, vegetarian or lacto ovo vegetarian diets was ruled out. Alcohol intake was lower than $\mathbf{4 0} \mathrm{g} /$ day for men and $20 \mathrm{~g} /$ day for women. Habitual drug intake in

TABLE I Clinical features of the patients

\begin{tabular}{lcc}
\hline & $\begin{array}{l}\text { Ulcerative } \\
\text { colitis } \\
(n=41)\end{array}$ & $\begin{array}{l}\text { Crohn's } \\
\text { disease } \\
(n=32)\end{array}$ \\
\hline Patients with first attack & 13 & 9 \\
Patients previously diagnosed & 18 & 7 \\
$\quad$ Intermittent attacks & 10 & 16 \\
Continuous symptoms & $5-456$ & $7-120$ \\
Duration of disease (months) & 25 & 12 \\
Nutritional status (30) & 12 & 15 \\
Good nutrition & 0 & 2 \\
Kwashiorkor like malnutrition & 4 & 3 \\
Marasmus & 0 & 4 \\
Mixed malnutrition & 5 & 10 \\
Previous surgery & 52 & 9 \\
Current drug therapy & 6 & 3 \\
Patients untreated & 0 & 3 \\
Steroids alone & 6 & 2 \\
Sulphasalazine alone & 1 & 4 \\
Metronidazole alone & 1 & 1 \\
Steroids+sulphasalazine & & \\
Steroids+metronidazole & & \\
Steroids+metronidazole + sulphasalazine & 1 & \\
\hline
\end{tabular}

TABLE II Plasma fatty acids $(F A)$ in ulcerative colitis (UC) as compared with controls

\begin{tabular}{|c|c|c|c|}
\hline$\%$ & $U C(n=41)$ & Controls $(n=107)$ & $p$ \\
\hline $16: 0^{\star}$ & $26.9(0.4)$ & $25 \cdot 2(0 \cdot 2)$ & 0.0012 \\
\hline $16: 1 \dagger$ & $1 \cdot 7[1 \cdot 1-2 \cdot 2]$ & $1 \cdot 7[1.5-1.9]$ & 0.4703 \\
\hline $18: 0+$ & $8 \cdot 2[8 \cdot 1-9 \cdot 3]$ & $10 \cdot 5[10 \cdot 0-10 \cdot 8]$ & $<0.00001$ \\
\hline $18: 1 \dagger$ & $22 \cdot 7[20 \cdot 5-24 \cdot 8]$ & $21 \cdot 9[20 \cdot 9-22 \cdot 8]$ & $0 \cdot 2870$ \\
\hline $18: 2 \mathrm{n} 6^{\star}$ & $26 \cdot 7(0 \cdot 7)$ & $27 \cdot 2(0 \cdot 4)$ & 0.6293 \\
\hline $18: 3 n 3 \dagger$ & $0.3[0.0-0.5]$ & $0.0[0.0-0.0]$ & 0.0143 \\
\hline 18:3n6† & $0.0[0.0-0.0]$ & $0.0[0.0-0.0]$ & 0.5597 \\
\hline $20: 2 n 6 \dagger$ & $0.0[0.0-0.3]$ & $0.1[0.0-0.3]$ & 0.0711 \\
\hline $20: 3 n 6^{\star}$ & $1 \cdot 9(0 \cdot 1)$ & $2 \cdot 6(0 \cdot 1)$ & 0.0001 \\
\hline $20: 4 n 6^{\star}$ & $7 \cdot 4(0.3)$ & $8.0(0.2)$ & $0 \cdot 1320$ \\
\hline $20: 5 n 3 \dagger$ & $0.3[0.0-0.5]$ & $0.2[0.0-0.4]$ & 0.3414 \\
\hline $22: 6 n 3 \dagger$ & $2 \cdot 2[1 \cdot 9-2 \cdot 8]$ & $1 \cdot 4[1 \cdot 3-1 \cdot 6]$ & $<0.00001$ \\
\hline $\mathrm{UNID}^{\star}$ & $131 \cdot 8(2 \cdot 0)$ & $131 \cdot 5(1 \cdot 1)$ & 0.9060 \\
\hline
\end{tabular}

^Mean (SEM) Student's $t$ test; † Median [95\% CI].

Mann-Whitney U test; UNID=unsaturation index. the previous three months of sample extraction was carefully ruled out, especially for hypolipemiant drugs, non-steroidal antiinflammatory drugs or oral contraceptives. Individuals taking trace elements or vitamin supplements in the previous six months were not included. Relatives of patients with inflammatory bowel disease were also excluded.

Informed consent was obtained from each patient. The study was performed in accordance with the $1975^{\circ}$ Declaration of Helsinki ethical guidelines and was approved by the Research and Ethical Committees of the Hospital.

\section{PLASMA FATTY ACID ASSAY}

In all patients and healthy controls, a $5 \mathrm{ml}$ venous blood sample for plasma fatty acid measurement was drawn after a 14 hour overnight fast at the same time that full clinical assessment was performed. Plasma was separated by centrifugation at $3000 \times g$ during five minutes and immediately frozen and stored at $-50^{\circ} \mathrm{C}$ under nitrogen atmosphere.

The plasma obtained was treated with $5 \mathrm{ml}$ of a chloroform:methanol $(2: 1 \mathrm{v} / \mathrm{v})$ mixture containing $50 \mathrm{mg} / \mathrm{l}$ butylhydroxy-toluene, $1.5 \mathrm{ml} 0.01 \mathrm{~N}$ $\mathrm{HCl}$, and $50 \mu \mathrm{l} \mathrm{MgCl}$ in water. The mixture was stirred for one minute in a tube mixer and then centrifugated at $3000 \times g$ for 10 minutes. The chloroform phase was separated by aspiration with a Pasteur pipette, and the aqueous phase was reextracted with $3 \mathrm{ml}$ chloroform:methanol mixture. After centrifugation, chloroform phases were mixed and evaporated to dryness under nitrogen atmosphere. ${ }^{3}$

Saponification and methylation of fatty acids were immediately carried out, using $14 \% \mathrm{BF}_{3}$ in methanol according to the Morrison and Smith procedure. ${ }^{32}$ Fatty acid methyl esters were quantified by gas liquid chromatography in a 5890A Hewlett-Packard chromatograph using a $30-\mathrm{m}$, wide bore column, $0.32 \mathrm{~mm}$ internal diameter, impregnated with SP-2330 as stationary phase. Initial oven temperature was $150^{\circ}$ which was maintained for eight minutes; afterwards, it was increased at a rate of $3 \%$ minute up to $210^{\circ} \mathrm{C}$. The identification and quantification of fatty acid methyl esters was possible by using an external standard (Sigma Co, St Louis, Mo, USA). Individual response factors were calculated for each fatty acid.

Fatty acids from $\mathrm{C} 14: 0$ to $\mathrm{C} 22: 6 \mathrm{n} 3$ were measured. Unidentified peaks accounted for less than $0.5 \%$ of total fatty acids. The desaturation index was calculated as previously described ${ }^{32}$ according to the formula:

$\mathrm{UNID}=\Sigma$ (fatty acid percentage $\times$ number of double bonds).

\section{STATISTICAL ANALYSIS}

For statistical analysis the Statistical Package for Social Sciences SPSS/PC+ (SPSS Inc, Chicago, Illinois, USA, 1985) was used. ${ }^{3+}$ Variables with normal distribution and homogeneous variance were compared by means of parametric tests, otherwise their non-parametric counterparts were used. To assess differences in plasma fatty acid percentages between patients and controls, 
the Student's $t$ test or Mann-Whitney U test were used, when necessary. One way analysis of variance with 'a posteriori' Scheffé test or Kruskall-Wallis one way analysis of variance by ranks were used, when necessary, to assess the influence of the severity of the disease upon fatty acid profile in these patients. When the Kruskall-Wallis test disclosed a significant $p$ value, the Mann-Whitney $U$ test was carried out in order to detect where the differences occur. Results are expressed as mean (SEM) or median and its $95 \%$ confidence interval ${ }^{35}$ for parametric and non-parametric variables respectively.

\section{Results}

The clinical features of the 73 patients included in the study are detailed in Table I. Ulcerative colitis involved the entire colon in 21 patients, the left colon in 12, and was confined to the rectum in eight. Crohn's disease was ileocolic in 10 cases, involved only the small bowel in nine patients, and 13 patients had colonic disease.

TABLE III Plasma fatty acids (FA) in Crohn's disease (CD) as compared with controls

\begin{tabular}{lccc}
\hline$\%$ & $C D(n=32)$ & Controls $(n=107)$ & \multicolumn{1}{c}{$p$} \\
\hline $16: 0^{\star}$ & $25 \cdot 6(0 \cdot 3)$ & $25 \cdot 2(0 \cdot 2)$ & $0 \cdot 4372$ \\
$16: 1 \dagger$ & $2 \cdot 1[1 \cdot 6-2 \cdot 8]$ & $1 \cdot 7[1 \cdot 5-1 \cdot 9]$ & $0 \cdot 0725$ \\
$18: 0 \dagger$ & $8 \cdot 3[7 \cdot 8-9 \cdot 4]$ & $10 \cdot 5[10 \cdot 0-10 \cdot 8]$ & $<0 \cdot 00001$ \\
$18: 1 \dagger$ & $23 \cdot 4[20 \cdot 9-25 \cdot 0]$ & $21.9[20 \cdot 9-22 \cdot 8]$ & 0.0997 \\
$18: 2 n 6^{\star}$ & $25 \cdot 8(0 \cdot 8)$ & $27 \cdot 2(0 \cdot 4)$ & $0 \cdot 1700$ \\
$18: 3 n 3 \dagger$ & $0 \cdot 7[0 \cdot 08-1 \cdot 4]$ & $0 \cdot 0[0 \cdot 0-0 \cdot 0]$ & $<0 \cdot 00001$ \\
$18: 3 n 6 \dagger$ & $0 \cdot 0[0 \cdot 0-0 \cdot 3]$ & $0 \cdot 0[0 \cdot 0-0 \cdot 0]$ & $0 \cdot 1954$ \\
$20: 2 n 6 \dagger$ & $0 \cdot 0[0 \cdot 0-0 \cdot 2]$ & $0 \cdot 1[0 \cdot 0-0 \cdot 3]$ & $0 \cdot 0340$ \\
$20: 3 n 6^{\star}$ & $2 \cdot 1(0 \cdot 1)$ & $2 \cdot 6(0 \cdot 1)$ & $0 \cdot 0041$ \\
$20: 4 n 6^{\star}$ & $7 \cdot 5(0 \cdot 3)$ & $8 \cdot 0(0 \cdot 2)$ & $0 \cdot 1920$ \\
$20: 5 n 3 \dagger$ & $0 \cdot 4[0 \cdot 0-0 \cdot 7]$ & $0 \cdot 2[0 \cdot 0-0 \cdot 4]$ & 0.1725 \\
$22: 6 n 3 \dagger$ & $3 \cdot 0[1 \cdot 7-3 \cdot 8]$ & $1 \cdot 4[1 \cdot 3-1 \cdot 6]$ & $<0 \cdot 00001$ \\
UNID $^{\star}$ & $136 \cdot 2(2 \cdot 5)$ & $131 \cdot 5(1 \cdot 1)$ & 0.0980 \\
\hline
\end{tabular}

*Mean (SEM) Student's $t$ test; $†$ Median [95\% CI].

Mann-Whitney U test; UNID=unsaturation index.

TABLE IV Plasma fatty acids $(F A)$ in ulcerative colitis. Influence of the activity of the disease

\begin{tabular}{|c|c|c|c|c|}
\hline$\%$ & $\operatorname{Mild}(n=12)$ & Moderate $(n=19)$ & Severe $(n=10)$ & $p$ \\
\hline $16: 0^{\star}$ & $25 \cdot 7(1 \cdot 1)$ & $27 \cdot 6(0 \cdot 3)$ & $27 \cdot 0(0.6)$ & $0 \cdot 1605$ \\
\hline $16: 1^{\star}$ & $1 \cdot 8(0 \cdot 2)$ & $1.9(0.3)$ & $1.7(0.3)$ & 0.8801 \\
\hline $18: 0 \dagger$ & $9 \cdot 8[8 \cdot 2-12 \cdot 0]$ & $8 \cdot 2[7 \cdot 6-9 \cdot 5]$ & $8 \cdot 1[7 \cdot 2-10 \cdot 0]$ & $0.0253 \neq 8$ \\
\hline $18: 1 †$ & $18 \cdot 8[15 \cdot 2-25 \cdot 4]$ & $22 \cdot 7[20 \cdot 5-28 \cdot 0]$ & $25 \cdot 1[21 \cdot 6-30 \cdot 1]$ & $0.0236 \mp$ \\
\hline $18: 2 n 6^{\star}$ & $27 \cdot 3(1 \cdot 3)$ & $26 \cdot 4(1 \cdot 2)$ & $26 \cdot 8(1 \cdot 4)$ & 0.8845 \\
\hline $18: 3 n 3^{\star}$ & $0.4(0.1)$ & $0.5(0.1)$ & $0.5(0.2)$ & $0 \cdot 8647$ \\
\hline $18: 3 n 6 t$ & $0.3[0.0-0.8]$ & $0.0[0.0-0.0]$ & $0.0[0.0-0.2]$ & $0.0013 \neq 8$ \\
\hline $20: 2 n 6 t$ & $0.2[0.0-0.5]$ & $0.0[0.0-0.3]$ & $0.0[0.0-0.5]$ & $0.2554^{+3}$ \\
\hline $20: 3 n 6^{\star}$ & $2.7(0 \cdot 2)$ & $1.6(0.1)$ & $1 \cdot 3(0 \cdot 2)$ & $0.0002 \neq \delta$ \\
\hline $20: 4 n 6^{\star}$ & $8 \cdot 8(0 \cdot 4)$ & $6.6(0.4)$ & $7 \cdot 2(0 \cdot 4)$ & $0.0243 \ddagger$ \\
\hline $20: 5 n 3^{\star}$ & $0 \cdot 6(0 \cdot 1)$ & $0 \cdot 3(0 \cdot 1)$ & $0.2(0.06)$ & 0.0622 \\
\hline $22: 6 n 3^{\star}$ & $2 \cdot 9(0 \cdot 1)$ & $2 \cdot 1(0 \cdot 2)$ & $2 \cdot 2(0 \cdot 1)$ & 0.0648 \\
\hline UNID* & $142.0(3.0)$ & $126 \cdot 5(3 \cdot 1)$ & $129 \cdot 6(2 \cdot 2)$ & $0.0031 \neq$ \\
\hline
\end{tabular}

${ }^{\star}$ Mean $($ SEM). One way analysis of variance + Scheffé test; + Median $[95 \% \mathrm{CI}]$. Kruskall-Wallis test + Mann-Whitney U test; $†$ Mild $v$ moderate; $₫$ Mild $v$ severe; UNID = unsaturation index.

TABLE V Plasma fatty acids $(F A)$ in Crohn's disease. Influence of the activity of the disease

\begin{tabular}{|c|c|c|c|c|}
\hline$\%$ & Mild $(n=15)$ & Moderate $(n=11)$ & Severe $(n=6)$ & $p$ \\
\hline $16: 0^{\star}$ & $25 \cdot 2(0 \cdot 4)$ & $25 \cdot 6(0 \cdot 6)$ & $26 \cdot 3(1 \cdot 2)$ & $0 \cdot 5419$ \\
\hline $16: 1^{\star}$ & $2 \cdot 2(0.3)$ & $2.8(1.0)$ & $1.6(0.5)$ & 0.2123 \\
\hline $18: 0^{\star}$ & $9 \cdot 1(0 \cdot 3)$ & $8 \cdot 5(0 \cdot 4)$ & $7.9(0.5)$ & $0 \cdot 2045$ \\
\hline $18: 1^{\star}$ & $21.4(1.0)$ & $23 \cdot 3(0 \cdot 8)$ & $28 \cdot 5(2 \cdot 5)$ & $0.006+\ddagger$ \\
\hline $18: 2 \mathrm{n} 6^{\star}$ & $26 \cdot 1(1 \cdot 2)$ & $26 \cdot 2(1 \cdot 3)$ & $24 \cdot 7(1.9)$ & 0.7929 \\
\hline $18: 3 n 3^{\star}$ & $1.0(0.2)$ & $0.9(0.2)$ & $0.7(0.3)$ & 0.7644 \\
\hline $18: 3 \mathrm{n} 6 \dagger$ & $0.2[0.0-0.4]$ & $0 \cdot 0[0 \cdot 0-0 \cdot 3]$ & $0 \cdot 0[0 \cdot 0-1 \cdot 1]$ & $0 \cdot 3943$ \\
\hline $20: 2 \mathrm{n} 6 \dagger$ & $0.2[0.0-0.4]$ & $0 \cdot 0[0 \cdot 0-0.05]$ & $0.0[0 \cdot 0-0.5]$ & $0 \cdot 0640$ \\
\hline $20: 3 n 6^{\star}$ & $2 \cdot 3(0 \cdot 2)$ & $2 \cdot 2(0 \cdot 2)$ & $1 \cdot 3(0 \cdot 2)$ & 0.0641 \\
\hline $20: 4 n 6^{\star}$ & $8 \cdot 2(0 \cdot 5)$ & $7 \cdot 4(0 \cdot 4)$ & $5 \cdot 9(0 \cdot 5)$ & $0 \cdot 0443 \ddagger$ \\
\hline $20: 5 n 3^{\star}$ & $0 \cdot 6(0 \cdot 1)$ & $0 \cdot 3(0 \cdot 1)$ & $0 \cdot 2(0 \cdot 1)$ & $0.0620^{\circ}$ \\
\hline $22: 6 n 3^{\star}$ & $3 \cdot 1(0 \cdot 3)$ & $2 \cdot 5(0.4)$ & $2 \cdot 2(0 \cdot 5)$ & 0.3760 \\
\hline UNID* & $142 \cdot 0(3 \cdot 0)$ & $134 \cdot 4(3 \cdot 3)$ & $124 \cdot 9(7 \cdot 8)$ & $0.0355 \ddagger$ \\
\hline
\end{tabular}

${ }^{\star}$ Mean $(\mathrm{SEM})$. One way analysis of variance + Scheffé test; $\nmid$ Median $[95 \% \mathrm{CI}]$. Kruskall-Wallis test + Mann-Whitney U test; $¥$ Mild $v$ severe. UNID=unsaturation index.
Four patients with Crohn's disease who had previous operations (three colectomies and one ileocolectomy), were included because of relapsing disease.

PLASMA FATTY ACIDS

Plasma percentages of the different fatty acids in patients with ulcerative colitis and Crohn's disease are shown in Tables II and III.

ULCERATIVE COLITIS (Table II)

The most striking finding in plasma fatty acid profile in ulcerative colitis patients was the marked increase in $\mathrm{n} 3$ polyunsaturated fatty acids, both the essential precursor $(\alpha$-linolenic acid $(\mathrm{C} 18: 3 \mathrm{n} 3)$ ) and the end product (docosahexaenoic acid (C22:6n3)).

In the $\mathrm{n} 6$ series, patients with ulcerative colitis showed low values of dihomo- $\tau$-linolenic acid (C20:3n6), whereas values of the essential precursor (linoleic acid (C18:2n6)) and the main product (arachidonic acid (C20:4n6)) showed no differences when compared with controls.

Palmitic acid (C16:0) concentrations were significantly higher in ulcerative colitis patients than in healthy individuals. Stearic acid (C18:0) was significantly lower in ulcerative colitis than in controls. There were no differences in monoenoic fatty acids between patients and controls.

The unsaturation index did not show differences between patients with ulcerative colitis and controls.

\section{CROHN'S DISEASE}

The plasma fatty acid profile in Crohn's disease was similar to that found in ulcerative colitis (Table III). As in ulcerative colitis, a significant increase in $\mathrm{n} 3$ polyunsaturated fatty acids ( $\alpha$ linolenic acid (C18:3n3) and docosahexaenoic acid $(\mathrm{C} 22: 6 \mathrm{n} 3)$ ) and a decrease in plasma dihomo- $\tau$-linolenic acid (C20:3n6), a long chain polyunsaturated fatty acids of the $\mathrm{n} 6$ series, was also observed.

When compared with healthy individuals, plasma concentrations of stearic acid $(\mathrm{C} 18: 0)$ was significantly decreased.

EFFECT OF THE ACTIVITY OF THE DISEASE

Fatty acid profile was related to the activity of the disease, both in ulcerative colitis (Table IV) and Crohn's disease patients (Table V). The plasma values of stearic acid (C18:0) and long chain $n 3$ and n6 polyunsaturated fatty acids decreased stepwise as the disease became more severe. This only reached statistical significance for stearic acid (C18:0) and long chain n6 polyunsaturated fatty acids in ulcerative colitis and for arachidonic acid (C20:4n6) in Crohn's disease.

The decrease in plasma long chain polyunsaturated fatty acids associated to the increase of disease activity, was more marked in the n6 series (arachidonic and dihomo- $\tau$-linolenic acid), especially in ulcerative colitis. It is remarkable that, in spite of the progressive fall in plasma docosahexaenoic acid values as inflammatory bowel disease became more severe, its mean 
value always remained above the mean value of this $\mathrm{n} 3$ polyunsaturated fatty acid in healthy individuals. It is also noteworthy that in mild disease, concentrations of long n6 polyunsaturated fatty acids, especially arachidonic acid, also remained above those in healthy controls. The decrease in plasma long chain and highly unsaturated fatty acids in those patients with more severe disease, which resulted in a significant reduction of the unsaturation index, was partly counterbalanced by a significant increase in the percentage of oleic acid (C18:1).

\section{Discussion}

The most striking result of this study is the increased plasma concentrations of the precursor $(\alpha$-linolenic acid) and the end product (docosahexaenoic acid) of the $n 3$ polyunsaturated fatty acid series in active ulcerative colitis and Crohn's disease. In addition, low concentrations of dihomo- $\tau$-linolenic (C20:3n6) acid were also found. When patients were grouped according to the severity of the attack, however, a stepwise fall in polyunsaturated fatty acids was observed as the disease became more severe. This was especially marked for long chain n6 polyunsaturated fatty acids in ulcerative colitis and Crohn's disease. It is remarkable that although concentrations of docosahexaenoic acid (C22: 6n3) also tend to decrease stepwise as disease activity increased, their mean concentrations never reach values below that of healthy controls.

This pattern of plasma fatty acids suggests that, in active inflammatory bowel disease, increased polyunsaturated fatty acid biosynthesis might coexist with increased fatty acid consumption. The finding of high plasma n3 polyunsaturated fatty acids concentrations would support the first part of this hypothesis; that is, the increase in polyunsaturated fatty acid biosynthesis. This phenomenon would be particularly evident in this fatty acid series because $n 3$ polyunsaturated fatty acids are preferential substrates for desaturases. ${ }^{136}$ The fact that high concentrations of $n 6$ fatty acids were also observed in patients with mild disease further supports the concept of an enhanced polyunsaturated fatty acid biosynthesis in inflammatory bowel disease.

The second part of the hypothesis - that is, the excessive consumption of fatty acids, might be supported by the stepwise fall of stearic acid (C18:0) and long chain polyunsaturated fatty acids, particularly those of the n6 series, observed as disease activity became more severe. Polyunsaturated fatty acid hypermetabolism may take place to meet the needs for cellular repair and to obtain energy ( $\beta$-oxidation) as in other hypercatabolic states. ${ }^{37}{ }^{38}$ Another possible explanation for the more marked decrease in plasma $n 6$, as compared with $n 3$ polyunsaturated fatty acids, might be an increased synthesis of arachidonic acid derived eicosanoids in the intestinal mucosa in active disease..$^{712}$ It may be argued that low essential fatty acid intake could account for the diminished long chain polyunsaturated fatty acids in severe disease. Plasma concentrations of both essential fatty acids, linoleic (C18:2n6), and $\alpha$-linolenic (C18:3n3), however, were not decreased even when disease was severe. To reinforce the suggestion of an enhanced polyunsaturated fatty acid synthesis, counterbalanced by hyperconsumption in active inflammatory bowel disease, studies have to be carried out in non-active patients.

A high intake of $n 3$ fatty acids, especially of the essential $\alpha$-linolenic acid, could be postulated as an explanation for the increased $n 3$ polyunsaturated fatty acids in inflammatory bowel disease. This was not the case in our patients, however, as they were eating a standard western diet. This type of diet contains negligible amounts of long chain $\mathrm{n} 3$ fatty acids (less than $1 \%$ of the total fatty acids consumed). ${ }^{39}$ In addition, these patients usually reduce their food intake when disease flares up. It could then be speculated that the high concentrations of $\alpha$ linolenic acid (which is exclusively from dietary origin), might be the result of a negative feed back effect upon delta- 6 desaturase activity, mediated by an excess of docosahexaenoic acid (C22:6n3), the final product of this series. ${ }^{+0-42}$

The high concentrations of palmitic acid (C16:0) in ulcerative colitis suggest an enhanced lipolysis caused by increased energy requirements, as occur in other hypercatabolic states. ${ }^{43+4}$ In this setting, it is difficult to explain the low plasma concentrations of stearic acid (C18:0). It might be speculated that this results in a diminished synthesis of stearic acid from palmitic acid (which would be preferentially oxidated) and/or an increased activity of delta-9desaturase to produce oleic acid.

Two previous reports have assessed plasma polyunsaturated fatty acid pattern in patients with Crohn's disease. Both studies represent selected populations of patients with Crohn's disease as they included patients with either ileal resection ${ }^{27}$ or malabsorption. ${ }^{26}$ In contrast with our results, these studies describe a pattern of essential fatty acid deficiency, probably related to malabsorption. Severe malabsorption seldom occurs in Crohn's disease.

Two studies ${ }^{45}$ have shown that in inflammatory bowel disease the concentrations of arachidonic acid (C20:4n6) in the inflamed colonic mucosa were increased. Moreover, in one $\mathrm{e}^{45}$ increased concentrations of docosahexaenoic acid (C22:6n3) were also found. These data are in agreement with our findings, and with the fact that plasma fatty acid pattern reflects the fatty acid composition of the tissues. ${ }^{47}$

The changes in $n 3$ and $n 6$ polyunsaturated fatty acid profile found in inflammatory bowel disease may be of relevance in the pathogenesis of the disease because they influence either tissue eicosanoid synthesis and the membrane lipid composition of the immunocompetent cells. ${ }^{18}$ It has been demonstrated that in vitro manipulation of fatty acid composition of lymphocytes can alter immune functions, such as cytotoxicity, antibody response, or cell to cell recognition. ${ }^{+8+9}$ In this context, the similar polyunsaturated fatty acids pattern found in ulcerative colitis and Crohn's disease suggests that both diseases might share a common pathogenic mechanism. It would be of interest to know whether this plasma fatty acid pattern, not previously 
reported in other disease states, ${ }^{50}$ is exclusive to inflammatory bowel disease or also occurs in other autoimmune conditions.

Based on the fact that eicosapentaenoate derived eicosanoids have attenuated proinflammatory activity as compared with arachidonate derived compounds, dietary $\mathrm{n} 3$ polyunsaturated fatty acid supplements (fish oil) have been successfully used in experimental animal models of inflammation ${ }^{21}$ and in patients with rheumatoid arthritis. ${ }^{22}$ According to this hypothesis, they have been administered in inflammatory bowel disease patients, but the results of various clinical trials are controversial..$^{23-25}$ Our finding of high plasma $\mathrm{n} 3$ polyunsaturated fatty acid concentrations in active inflammatory bowel disease raises some doubts on the use of high doses of $n 3$ polyunsaturated fatty acids in the treatment of inflammatory bowel disease.

Supported by grant $88 / 2074$ of the FISss, National Institute of Health, Spain. This paper was presented at the Annual Meeting of the American Gastroenterological Association, May 1990, San Antonio, Texas and published as an abstract in Gastroenterology 1990; 98: A411.

1 Mead JF. The non-eicosanoid functions of the essential fatty acids. F Lipid Res 1984; 25: 1517-21.

2 Sandermann $H$. Regulation of membrane enzymes by lipids. Biochim Biophys Acta 1978; 515: 209-37.

3 Falardeau P, Hamberg M, Samuelsson B. Metabolism of $8,11,14$-eicosatrienoic acid in human platelets. Biochim Biophys Acta 1976; 441: 193-200.

4 Samuelsson B, Goldyne M, Granstrom E, Hamberg M Hammarstrom S, Malmsten C. Prostaglandins and Hammarstrom S, Malmsten C. Prostaglandins

5 Samuelsson B. Leukotrienes: mediators of immediate hypersensitivity reactions and inflammation. Science 1983; 220 568-75

6 Needleman P, Raz A, Minkes MS, Ferrendelli JA, Sprecher $\mathrm{H}$. Triene prostaglandins: Prostacyclin and thromboxane
biosynthesis and unique biological properties. Proc Natl Acad Sci USA 1979; 76: 944-8.

7 Rask-Madsen J. Eicosanoids in inflammatory bowel disease: advances, pitfalls and therapeutic consequences. Eur $\mathcal{F}$ Gastroenterol Hepatol 1989; 1: 133-65.

8 Lauritsen K, Laursen LS, Bukhave K, Rask-Madsen J. In vivo profiles of eicosanoids in ulcerative colitis, Crohn's colitis and Clostridium Difficile colitis. Gastroenterology colitis and Clost

9 Donowitz $M$. Arachidonic acid metabolites and their role in inflammatory bowel disease. Gastroenterology 1985; 88 580-7.

10 Hawkey CJ, Rampton DS. Prostalandins and the gastrointestinal mucosa: Are they important in its functions, disease or treatment? Gastroenterology 1985; 89: 1162-88.

11 Sharon P, Stenson WF. Enhanced synthesis of leukotriene $B_{4}$ by colonic mucosa in inflammatory bowel disease. Gastroenterology 1984; 86: 453-60.

12 Lauritsen K, Laursen LS, Bukhave K, Rask-Madsen J. In vivo effects of orally administered prednisolone on prostaglandin and leucotriene production in ulcerative colitis. Gut glandin and leuco

13 Holman RT. Nutritional and metabolic interrelationships between fatty acids. Federation Proc 1964; 23: 1062-7.

14 Sprecher $\mathrm{H}$. The influence of dietary alterations, fasting and competitive interactions on the microsomal chain elongation of fatty acids. Biochim Biophys Acta 1974; 360: 113-23.

15 Budowski P, Crawford MA. $\alpha$-linolenic acid as a regulator of the metabolism of arachidonic acid: dietary implications of the ratio, n-6:n-3 fatty acids. Proc Nutr Soc 1985; 44: 221-9.

16 Adam O, Wolfram G, Zöllner N. Effect of $\alpha$-linolenic acid in the human diet of linoleic acid metabolism and prostaglandin biosynthesis. 7 Lipid Res 1986; 27: 421-6.

17 Fischer S, Weber PC. Thromboxane $\mathrm{A}_{3}\left(\mathrm{TXA}_{3}\right)$ is formed in human platelets after dietary eicosapentaenoic acid (C20:5n3). Biochem Biophys Res Commun 1983; 116: 1091-9.

18 Fischer $S$, Weber PC. Prostaglandin $\mathrm{I}_{3}$ is formed in vivo in man after dietary eicosapentaenoic acid. Nature 1984; 307: 165-8.

19 Lee TH, Hoover RL, Williams JD, Sperling RI, Ravalese II $\mathrm{J}$, Spur BW, et al. Effect of dietary enrichment with eicosapentaenoic and docosahexaenoic acids on in vitr neutrophil and monocyte leukotriene generation and neutrophil function. N Engl f Med 1985; 312: 1217-24.

20 McColl SR, Cleland LG, Whitehouse MW, Vernon-Roberts B. Effect of dietary polyunsaturated fatty acid (PUFA) supplementation on adjuvant induced polyarthritis in rats. 7 Rheumatol 1987; 14: 197-201.
21 Vilaseca J, Salas A, Guarner F, Rodriguez R, Martinez M, Malagelada J-R. Dietary fish oil reduces progession of chronic inflammatory lesions in a rat model of granulomatous colitis. Gut 1990; 31: 539-44.

22 Kremer JM, Jubiz W, Michalek A, Rynes RI, Barttholomew LE, Bigaouette J, et al. Fish-oil fatty acid supplementation in active rheumatoid arthritis. Ann Intern Med 1987; 106: in active

23 Lorenz R, Weber PC, Szimnau P, Heldwein W, Strasser T, Loeschke K. Supplementation with n-3 fatty acids in chronic inflammatory bowel disease - a randomized, placebo-controlled, double-blind cross-over trial. F Intern Med 1989; 225 (suppl 1): 225-32.

24 Tobin A, Suzuky Y, O'Morain C. Controlled double blind cross over study of eicosapentaenoic acid (EPA) in chronic ulcerative colitis (UC). Gastroenterology 1990; 98: A207.

25 Hawthorne AB, Daneshmend TK, Hawkey CJ, Shaheen MZ, Edwards TJ, Filipowicz BL, et al. Fish oil in ulcerative colitis: final results of a controlled clinical trial. Gastroenterology 1990; 98: A174.

26 Färkkilä MA, Tilvis RS, Miettinen TA. Plasma fatty acid composition in patients with ileal dysfunction. Scand $\mathcal{J}$

27 Tribl B, Frotz S, Widhalm F, Lochs H. Serum fatty acid pattern in patients with Crohn's disease. Clin Nutr 1988; 7 (suppl): 80

28 Truelove SC, Witts LJ. Cortisone in ulcerative colitis. Final report on a therapeutic trial. BMF 1955; 2: 1041-6.

29 Van Hees PAM, Van Elteren PH, Van Lier HJJ, Van Tongeren JHM. An index of inflammatory activity in patients with Crohn's disease. Gut 1980; 21: 279-86.

30 Gassull MA, Cabré E, Vilar L, Alastrue A, Montserrat A. Protein-energy malnutrition: An integral approach and a simple new classification. Hum Nutr Clin Nutr 1984; 38: simple new

31 Haan GH, Van Der Heide S, Wolteers RG. Analysis of fatty acids from human lipids by thin layer chromatography. f Chromatogr 1979; 162: 261-7.

32 Morrison MR, Smith LM. Preparation of fatty acid methyl esters and dimethylacetals from lipids with boron fluoride methanol. $\mathcal{F}$ Lipid Res 1964; 5: 600-8.

33 Galli C, White HB, Paoletti R. Brain lipid modifications induced by essential fatty acid deficiency in growing male and female rats. $\mathcal{F}$ Neurochem $1970 ; 17: 347-55$.

34 Norusis MJ. Advanced statistics SPSSIPC + for the IBM PC/ $X T / A T$. Chicago: SPSSinc, 1986.

35 Diem K, Lentner C, eds. Documenta Geigy. Scientific tables. 7th ed. Basel: Geigy, 1970

36 Brenner RR, Peluffo RO. Effect of saturated and unsaturated fatty acids on the desaturation in vitro of palmitic, stearic, oleic, linoleic and linolenic acids. F Biol Chem 1966; 241: 5213-9.

37 Hartig W, Matkowitz R, Faust H. Post-agression metabolism: hormonal and metabolic aspects. $\mathcal{F}$ Clin Nutr Gastroenterol 1986; 1: 255-60.

38 Kärki T, Hakkola E, Hassinen IE, Hiltunen JK. $\beta$-oxidation of polyunsaturated fatty acids in peroxisomes. FEBS Lett 1987; 215: 228-32.

39 Bang HO, Dyerberg J, Hiorne N. The composition of food consumed by Greenland Eskimos. Acta Med Scand 1976; 200: 69-73.

40 Bivins BA, Bell RM, Rapp RP, Griffen WO. Linoleic acid versus linolenic acid: What is essential? $\mathcal{F} P E N$ 1983; 7: 473-8

1 Brenner RR, Peluffo RO, Nervi AM, De Tomas ME. Competitive effect of $\alpha$ and $\tau$-linolenyl-CoA and arachidonylCoA in linoleyl-CoA desaturation to $\tau$-linolenyl CoA. Biochim Biophys Acta 1969; 176: 420-2.

42 Brenner RR, Peluffo RO. Inhibitory effect of docosa-4,7,10, 13,16,19-hexaenoic acid upon the oxidative desaturation of linoleic into $\tau$-linolenic acid and of $\alpha$-linolenic acid into octadeca-6,9,12,15-tetraenoic acid. Biochim Biophys Acta 1967; 137: 184-6.

43 Maldonado J, Pita ML, Narbona E, Gil A, Molina JA. Changes in the serum fatty acid patterns of injured and infected children receiving fat-free parenteral nutrition. $\mathcal{F}$ Clin Nutr Gastroenterol 1987; 2: 105-12.

44 Maldonado J, Gil A, Faus MJ, Pita ML, Molina JA. Serum fatty acids and amino acids. Are they markers of the severity and outcome in trauma children? $\mathscr{f}$ Clin Nutr Gastroenterol 1987; $2: 74-80$.

45 Nishida T, Miwa H, Shigematsu A, Yamamoto $M$, Iida $M$, Fujishima $M$. Increased arachidonic acid composition of phospholipids in colonic mucosa from patients with active ulcerative colitis. Gut 1987; 28: 1002-7.

46 Pacheco S, Hillier K, Smith C. Increased arachidonic acid levels in phospholipids of human colonic mucosa in inflammatory bowel disease. Clin $S_{c i}$ 1987; 73: 361-4

47 Paulsrud JR, Pensler R, Whitten CF, Stewart S, Holman RT. Essential fatty acid deficiency in infants induced by fat-free intravenous feeding. Am $\mathcal{F}$ Clin Nutr 1972; 25: 897-904.

48 Kinsella JE, Lokesh B, Broughton S, Whelan J. Dietary polyunsaturated fatty acids and eicosanoids: Potential effects on the modulation of inflammatory and immune cells: An overview. Nutrition 1990; 6: 24-44.

49 Smith AD, Conroy DM, Belin J, Stubbs CD. Membrane lipid modification and immune function. Proc Nutr Soc 1985; 44: 201-9.

50 Holman RT. Polyunsaturated fatty acid profiles in human disease. Curr Top Nutr Dis 1981; 5: 25-42. 